Review

\title{
Dental follicle stem cells and tissue engineering
}

\author{
Masaki J. Honda ${ }^{1,2)}$, Mari Imaizumi ${ }^{1)}$, Shuhei Tsuchiya ${ }^{1)}$ and Christian Morsczeck ${ }^{3)}$ \\ ${ }^{1)}$ Department of Anatomy, Nihon University School of Dentistry, Tokyo, Japan \\ ${ }^{2)}$ Division of Functional Morphology, Dental Research Center, Nihon University School of Dentistry, \\ Tokyo, Japan \\ ${ }^{3)}$ Department of Operative Dentistry and Periodontology, University Hospital Regensburg, \\ Regensburg, Germany
}

(Received 22 October and accepted 16 November 2010)

\begin{abstract}
Adult stem cells are multipotent and can be induced experimentally to differentiate into various cell lineages. Such cells are therefore a key part of achieving the promise of tissue regeneration. The most studied stem cells are those of the hematopoietic and mesenchymal lineages. Recently, mesenchymal stem cells were demonstrated in dental tissues, including dental pulp, periodontal ligament, and dental follicle. The dental follicle is a loose connective tissue that surrounds the developing tooth. Dental follicle stem cells could therefore be a cell source for mesenchymal stem cells. Indeed, dental follicle is present in impacted teeth, which are commonly extracted and disposed of as medical waste in dental practice. Dental follicle stem cells can be isolated and grown under defined tissue culture conditions, and recent characterization of these stem cells has increased their potential for use in tissue engineering applications, including periodontal and bone regeneration. This review describes current knowledge and recent developments in dental follicle stem cells and their application. (J Oral Sci 52, 541-552, 2010)
\end{abstract}

Keywords: bone regeneration; dental follicle; stem cells; tissue engineering; periodontal regeneration.

Correspondence to Dr. Masaki J. Honda, Department of Anatomy, Nihon University School of Dentistry, 1-8-13 Kanda-Surugadai, Chiyoda-ku, Tokyo 101-8310, Japan

Tel: +81-3-3219-8121

Fax: +81-3-3219-8319

E-mail: honda-ms@dent.nihon-u.ac.jp

\section{Introduction}

New approaches in tissue engineering are being developed to reconstruct and restore the function of damaged or diseased tissues and organs (1). The term "tissue engineering" was coined in 1993 by Langer and Vacanti (1) to describe the process by which tissues and organs are regenerated by cell transplantation with or without a scaffold. Almost 20 years later, tissue engineering has not advanced as hoped, despite many important achievements.

In dentistry, interest in tissue engineering research has increased rapidly among researchers and institutes. One reason for this is that dentists are familiar with tissue regeneration techniques, such as those that use tertiary dentin in dental pulp and periodontium in guided tissue regeneration, which is now common in dental hospitals (23). Furthermore, the development of techniques to generate whole teeth is ongoing (4-7). A key factor in perfecting this technology within the context of modern tissue engineering is the use of adult stem cells.

Stem cells are defined by their capacity to generate daughter cells with different and more restricted properties. In human postnatal dental tissue, five different sources of mesenchymal stem cells (MSCs) have been already identified: dental pulp (8-9), periodontal ligament (10), exfoliated deciduous teeth (11), dental follicle (DF) (12), and root apical papilla (13). These dental stem cells are derived from the neural crest, and thus have a different origin from bone marrow-derived MSCs, which are derived from mesoderm. On the other hand epithelial stem cells have not been identified in postnatal dental tissues. However, we recently demonstrated that the epithelial rest 
of Malassez (ERM) can generate enamel tissues (14), which suggests that epithelial stem cells may indeed be present in ERM (manuscript in preparation).

This review will focus on dental follicle stem cells (DFSCs) because of the alternative potential applications for these cells in bone and periodontal tissue engineering. As compared with bone marrow-derived MSCs, DFSCs are easily isolated from impacted teeth and readily grown under culture conditions. Harvesting of DFSCs from extracted teeth is noninvasive, although tooth extraction itself is an invasive technique.

\section{Function of dental follicle during tooth development}

The tooth is a complex organ consisting of distinctly different hard and soft tissue areas, including enamel, dentin, cementum, and pulp. The formation of the hard tissue structures is controlled by ameloblasts, odontoblasts, cementoblasts, and cell differentiation and morphogenesis is regulated by reciprocal epithelial-mesenchymal interaction (15). Teeth have the specific feature of being the only organ that penetrates from the host's internal tissue, ie, the jawbone, through the "oral integumentary layer" and into the oral cavity. Tooth roots within the jawbone are firmly anchored in the alveolar bone proper,

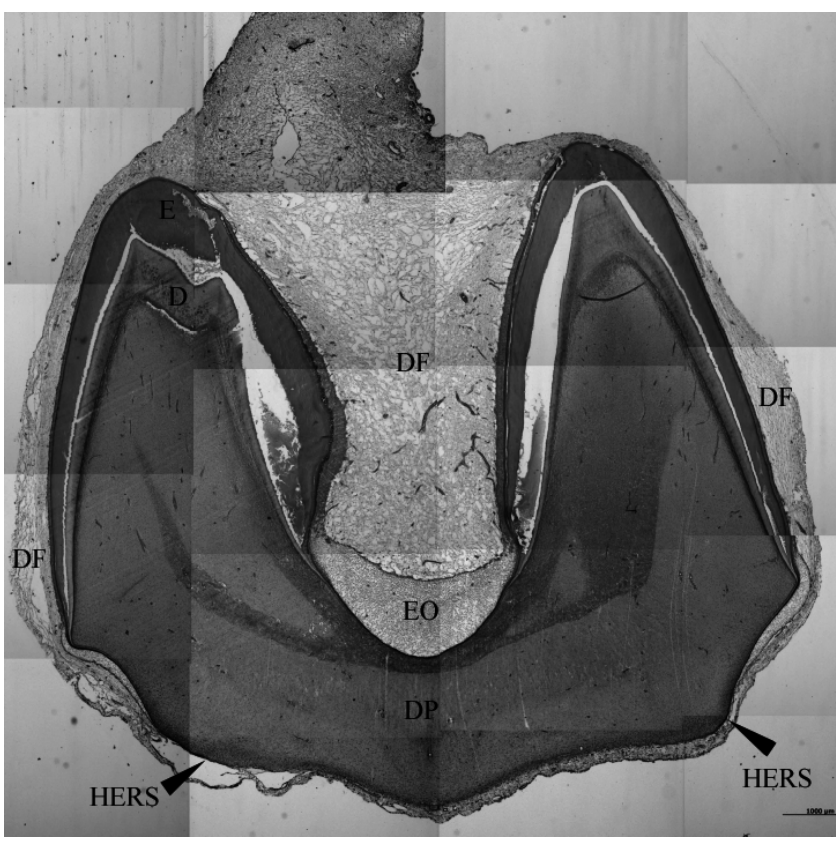

Fig. 1 Hematoxylin-eosin stained section of a porcine third molar tooth during early crown formation. The dental follicle layer surrounds the outside tooth. Abbreviations: dental follicle (DF), enamel organ (EO), dental pulp (DP), enamel (E), dentin (D), and Hertwig's epithelial root sheath (HERS, arrows). and a thin layer of membrane, called the periodontal ligament (PDL), resides between the tooth and bone. The PDL is essential for many functions that support the tooth.

During root development, cementogenesis begins during root formation. During this stage, the inner and outer enamel epithelia fuse to form the bilayered Hertwig's epithelial root sheath (HERS), which then induces differentiation of DFSCs into cementoblasts or osteoblasts (16-18). According to classical theory, DFSCs are the origin of the periodontium, including the cementum, PDL, and alveolar bone (19-22), and this developmental cascade confirms the existence of stem cells in the dental follicle. Although one study suggested that cementoblasts may arise from HERS, (18), other research has indicated that all cementoblasts arise from DFSCs (17). The DF is a loose connective tissue sac derived from ectomesenchymal tissues. It surrounds the developing tooth and plays different roles during the life of a tooth (23-25) (Fig. 1). The DF is formed at the cap stage of tooth germ development by an ectomesenchymal progenitor cell population originating from cranial neural crest cells $(20,25)$. In addition to its function in periodontium development, the DF is also critical for the coordination of tooth eruption $(26,27)$. During the tooth eruptive process, it remains adjacent to the tooth crown of unerupted or impacted teeth (28). The $\mathrm{DF}$ also regulates osteoclastogenesis and osteogenesis for eruption. Alternatively, under pathological conditions, the DF can proliferate into stratified squamous epithelium to generate dental cysts (29). Hence, it has several key functions in both the development of the periodontium and resorption of bone during tooth development.

\section{Mesenchymal stem cells in the dental follicle}

Recently, the multiple differentiation potential of adult stem cells has been extensively studied in basic research and for therapeutic use. The most studied adult stem cell types are hematopoietic stem cells (HSCs) and mesenchymal stem cells (MSCs) (30). MSCs possess the capacity for self-renewal and differentiation into a variety of cells, including osteocytes, adipocytes, chondrocytes (30), myocytes (31), and neurons (32). Moreover, MSCs support hematopoiesis and enhance the engraftment of HSCs after co-transplantation, and both experimental and clinical studies clearly show that MSCs reduce the incidence of graft-versus-host disease (33-34). These data suggest that MSCs are a valuable cell source for cell-based tissueengineering therapy. However, the search for alternative sources of MSCs is of considerable importance because bone marrow aspiration is an invasive procedure for obtaining MSCs, and there are significant age-related 
decreases in the frequency and differentiation potential of adult stem cells (35). One of the most promising sources of MSCs is from tissues discarded during the course of medical practice. Umbilical cord and umbilical cord blood are particularly advantageous because they can be obtained noninvasively $(36,37)$. As compared with umbilical cord, umbilical cord blood appears to be a less common source for MSCs (36). Umbilical cord contains two arteries (the UCAs) and one vein (the UCV) surrounded by mucoid connective tissue known as Wharton's jelly (UCWJ). We demonstrated that MSCs from UCA, UCV, and Wharton's jelly have multiple differentiation potential, including osteoblast, adipocyte, and chondrocyte generation. Furthermore, cells derived from the UCV have a high colony-forming unit-fibroblast (CFU-F) frequency and slow proliferation rate, which suggests that UCV-derived cells have the greatest potential as a source for MSCs (37). However, the feasibility of tissue engineered from MSCs derived from UCV, UCA, and UCWJ remains to be evaluated in clinical studies.

Most people have an impacted third molar that does not cause occlusion and subsequently have the impacted tooth extracted to avoid inflammation or orthodontic therapy. Such extracted teeth usually contain DF and are commonly discarded as medical waste. Hence, the DF is a candidate source for isolating MSCs. Recent evidence has suggested that MSCs are present in the DF of the tooth germ at various stages of development in different species (12,3842). As with other cell types, DFSCs adhere to plastic and form colonies in vitro. Handa et al. (40) were the first to report the existence of progenitor cells in bovine DF after transplantation. Cultured bovine DFSCs at the root-forming stage, in combination with hydroxyapatite, successfully generated cementum tissues and fibroblasts in vivo. Interestingly, cementum formation was observed only at the interface of the hydroxyapatite beads in the implants. Unlike alveolar osteoblasts, DFSCs do not form bone tissue by this method. Although it is unclear whether DFSCs have the characteristics of mesenchymal stem cells, they are clearly progenitor cells for cementoblasts (40). Human DF progenitor cells were also reported in the DF of wisdom teeth at the root-formation stage (42). Subsequently, mouse DFSCs at the crown-formation stage were shown to differentiate into osteogenic, adipogenic, and chondrogenic lineages (43), while another study showed that rat DFSCs have the capacity for osteogenesis, adipogenesis, and neurogenesis, but not chondrogenesis (12). Thereafter, postnatal MSCs from human dental tissue such as DF at the apex of tooth root, periodontal ligament, and dental pulp were isolated and compared to various other dental stem cells (41). The results showed that DFSCs have excellent proliferation rates and a capacity for osteogenesis and adipogenesis (41); however, their capacity for chondrogenesis remains unknown. Another study examined the differentiation capacity of human DFSCs during early root development. Under specific culture conditions, these cells differentiated toward multiple mesenchymal-derived cell types, such as osteoblasts, chondrocytes, and adipocytes (44). Finally, human DFSCs were found to have osteogenic differentiation capacity, but no adipose differentiation was detected. However, in that study, the observation period after induction was only 14 days, which might be shorter than the induction period. Chondrogenic differentiation was also not detected (45). These results indicate that MSCs reside in DF, but vary with respect to differentiation capacities across species and development stage (e.g., the crown- or root-formation stages). To elucidate this apparent multiple-differentiation potential of DFSCs, it might be necessary to clarify the differentiation ability of homogeneous cell populations derived from a single cell. Human studies using clonal cells from the DF may explain the discrepancies in previous results.

We designed an experiment to examine the differentiation capacity of DFSCs, using clonal expansion by limiting dilution (46). We obtained 12 single cell-derived cell populations that formed CFU-Fs in vitro. Each clonal cell population uniformly displayed one of three distinct morphologies under phase-contrast microscopy, which we termed HDF1, HDF2, and HDF3. Under tissue culture conditions, only HDF2 was spindle-shaped and had small processes consistent with periodontal ligament cells and bone marrow-derived cells. The other cell types had a polygonal morphology, and HDF1 cells were smaller than HDF3 cells (Fig. 2). Cell size is related to cell cycle (47), proliferation $(48,49)$, and differentiation $(50,51)$; smaller cells are more likely to have stem cell properties, and larger cells are more likely to be differentiated (52). Gene expression patterns in all HDFs also varied in our RT-PCR analysis.

Next, we examined the stem cell potential of the three HDF clonal populations (46). While all three proliferated in culture for more than 15 passages, proliferation assays showed that HDF1 cells had a higher proliferation potential than did HDF2 and HDF3 cells at six passages. All three cell populations could differentiate along the osteogenic (Fig. 3) and adipogenic lineages (Fig. 4) at six passages, but with very different potentials; HDF1 cells showed the highest osteogenic differentiation potential. All cell populations could also be driven to differentiate into adipocytes, although HDF3 cells had the highest propensity to differentiate along this pathway. However, none of the three clonal populations showed chondrocyte differentiation 

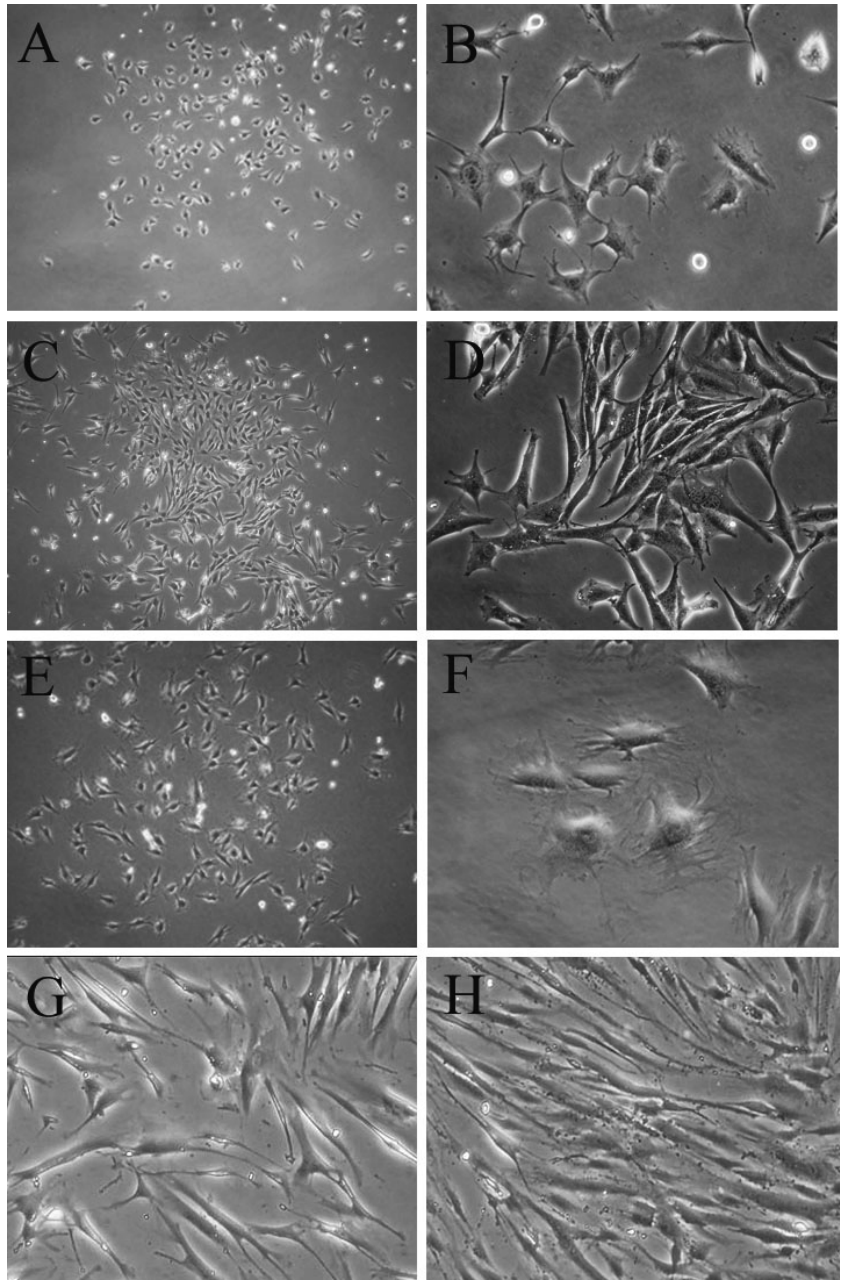

Fig. 2 Cell morphology of human dental follicle (HDF) stem cells. HDF1 cells have a polygonal cell morphology (A and B) and are smaller than HDF3 cells. HDF2 cells have a spindle shape $(C$ and $D)$ that resembles fibroblastic cells. HDF3 cells are also polygonal (E and F). Human periodontal ligament cells are spindleshaped $(\mathrm{G})$. Human bone marrow-derived mesenchymal cells have a fibroblastic spindle shape $(\mathrm{H})$.

under culture conditions that have produced chondrocyte lineage cells from other stem cell populations. Because all three HDF cell types showed multiple differentiation potential, our studies suggest that the DF contains heterogeneous stem cell populations. In fact, of four studies that tested the differentiation capacity of human DFSCs $(41,44,45,53)$, only one demonstrated differentiation into chondrocytes (44), which suggests that the DFSCs obtained in our study are already committed to an osteogenic or adipogenic lineage. In other words, in DFSCs, the ramification point between osteoblast and adipocyte lineages is later than that of osteogenic and chondrogenic lineages.

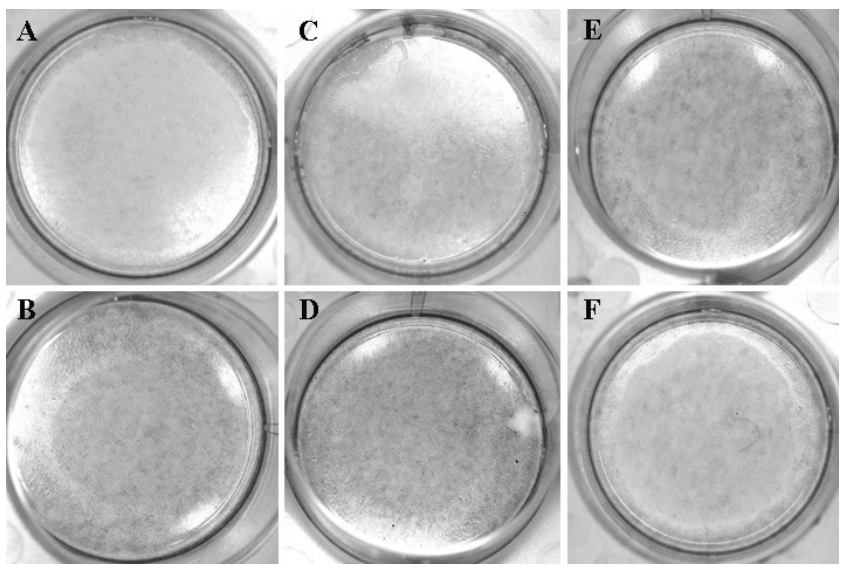

Fig. 3 Osteogenic differentiation in clonal human dental follicle (HDF) stem cell populations, as measured by mineralization potential. HDFs were subcultured in growth medium for 28 days (upper panels) and subsequently subcultured with osteogenic induction medium for 14 days (lower panels). In HDF1 and HDF2 cells in osteogenic induction medium, calcified extracellular matrix stained positive for alizarin red.

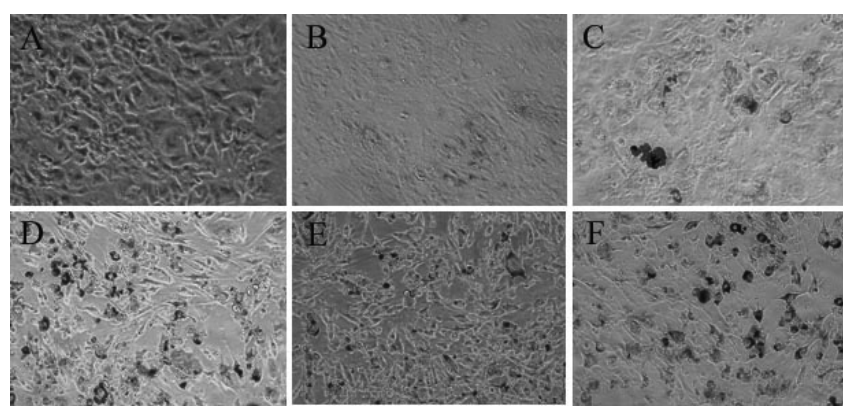

Fig. 4 Adipogenic differentiation capacity of dental follicle stem cells. Intracellular oil droplets were stained by Oil Red $\mathrm{O}$ in HDF3 cells cultured in growth medium (upper panels). All HDFs treated with adipogenic induction medium for 14 days were stained using Oil red $\mathrm{O}$ (lower panels).

There is, however, one report of heterogeneous DFSCs. Using SV40 transfection from miceDF, Luan et al. (43) generated three distinct immortalized cell lines that were vastly different in cell shape, alkaline phosphatase activity, mineralization pattern, and gene expression pattern; they were also clearly different from a same-stage, alveolar bonederived cell line (43). Interestingly, all their cell lines showed remarkably different potentials regarding mineralization characteristics in vitro. However, their study did not evaluate the tissue-forming capability of these cell populations (43). In addition, although it is 

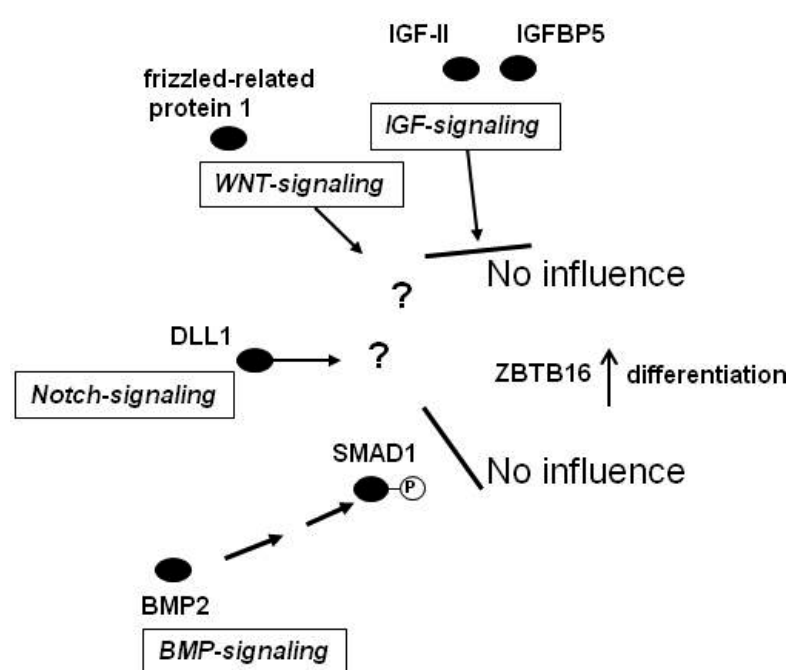

Fig. 5 Possible molecular mechanisms of osteogenic differentiation in dental follicle stem cells. Recent transcriptomic and proteomic studies revealed that BMP, Notch, WNT, and IGF signaling may control the progress of differentiation. However, the transcription factor ZBTB16, which is only expressed during cell differentiation, was not induced by BMP2 or IGF-II.

known that the DF contains heterogeneous stem cells, the question remains as to whether alveolar bone, cementum, and periodontal ligament can arise from these stem cells differentiating at the target tissue.

The switch of stem and progenitor cells from proliferation to differentiation is probably a crucial step in tissue development (54) and is therefore a key mechanism to understand if novel tissue engineering techniques are to be developed. Appropriately triggered DF can differentiate toward a cementoblast, osteoblast, or periodontal ligament lineage. However, the factors and mechanisms that regulate follicle cell differentiation remain undefined. Morsczeck et al. (42) demonstrated that human DFSCs are capable of differentiating into periodontal tissues in vivo, while Yokoi et al. (38) found that immortalized DFSCs isolated from mouse incisor tooth germs have the capacity to generate periodontal tissue in vivo. We reported that the gene expression patterns of DFSCs are consistent with those of PDL fibroblasts after culturing on collagen I matrix (55). Furthermore, several key genes, including DLX3 (56), transcription factor ZBTB16, and NR4A3 (57), have been implicated in the switch from undifferentiated status to differentiation lineage. The mechanisms of differentiation from stem cells to periodontal ligament, cementoblasts, and osteoblasts is expected to be elucidated in the future (Fig. 5).

If MSCs are to be used in clinical trials, we must ensure that they maintain a normal karyotype to avoid possible malignant tumor formation after transplantation. HDF1, 2 , and 3 cells derived from DF at 15 passages were analyzed for chromosomal G-banding by a commercial testing laboratory. The karyotypes in three tested DFSCs lines were surprisingly abnormal (unpublished data). Other studies isolated and expanded MSCs from second-trimester amniotic fluid for prenatal diagnosis. The karyotype of the MSCs was analyzed at the fourth and six passages and remained genetically stable (58). Moreover, gingival tissuederived MSCs showed normal karyotypes at passages 6 and 16. All MSCs had a normal diploid number of chromosomes (2n, $n=23$ ) (59). However, these results from other research groups are not consistent with ours, perhaps due to methodological differences in the isolation method (MSCs were divided into single cells in most of the other studies) and the region from which the MSCs were obtained. We have to determine the passage number at which the DFSCs chromosomes became abnormal.

Furthermore, although DFSCs have been extensively studied, many key points remain unresolved, such as the exact location of the obtained DFSCs. It has been suggested that MSCs reside around small blood vessels and are part of pericytes (60-63). Crisan et al. (59) proved that MSCs found throughout fetal and adult tissues are members of the pericyte family of cells. Ultimately, several dental MSC lines were developed and analyzed; however, the different tissue-forming potentials among them remain unknown. DFSCs seem to have the ability to generate hard tissue and/or periodontal ligament-tissue at ectopic sites in immunodeficient mice. In the next phase of research, investigators should examine the tissue-forming potential of DFSCs within periodontal and bone defects that are presumed to be associated with clinical disease. The next chapter addresses these issues in terms of tissue-forming capability.

\section{Bone-tissue-forming capability of dental follicle cells}

A key factor in successfully elucidating the cellular basis of tissue regeneration is determining the multipotential capabilities of stem cells to differentiate into desired target tissues (64). Recently, considerable attention has focused on the role of MSCs in bone formation, with the hope that they might serve as a possible source of stable differentiated osteoblasts. In dental practice, bone diseases and defects are common. Such patients are usually treated with autogenous bone grafts or artificial materials such as hydroxyapatite. Bone-tissue engineering has emerged as a tool with the potential to replace autologous tissue grafting in restoring lost tissue (65). Although BMSCs have 
been thoroughly studied for their clinical application in generating new bone, a possible similar role for DFSCs in bone repair of critical-size defects remains to be investigated. As mentioned above, DFSCs have the capacity to induce calcification in vitro (42) and in vivo (39). Thus, new bone formation for typical bone defects might be possible using stem cells derived from DFSCs.

We designed two studies to examine the tissue-forming capability of DFSCs in vivo. First, we investigated the potential of porcine DFSCs for bone formation by means of cell transplantation in a critical-size defect created in

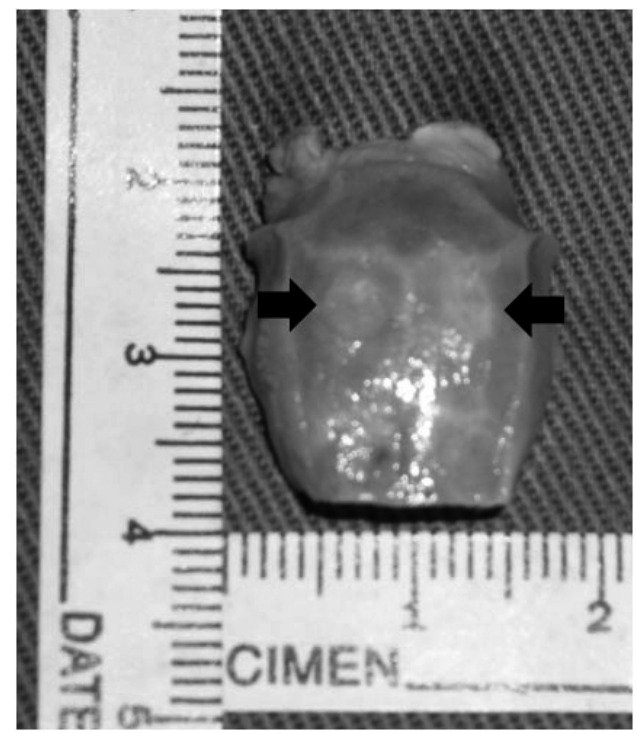

Fig. 6 In vivo new bone formation (arrows) after cell transplantation in surgically created calvarial defects in immunosuppressed rat.

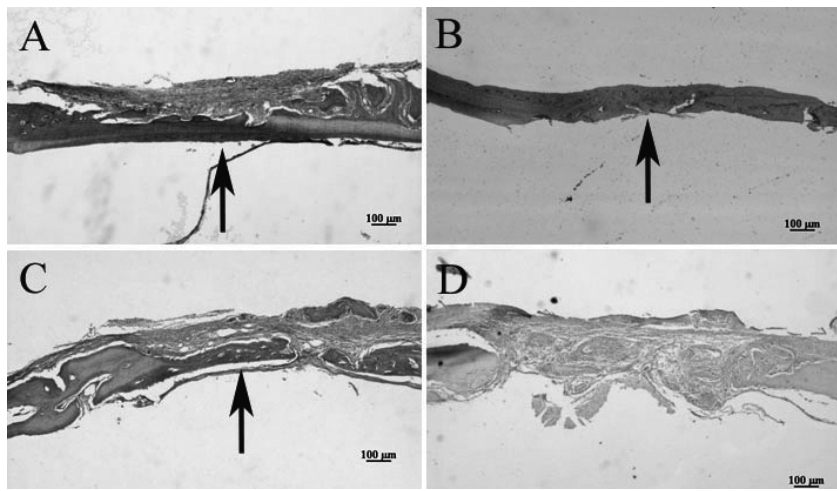

Fig. 7 (A)-(D) Panoramic view of surgically created calvarial defects in immunosuppressed rat 4 weeks after cell transplantation in tissue stained with hematoxylineosin. (A) HDF1 implant, (B) HDF2 implant, (C) HDF3 implant, (D) no cell implant. calvaria of immunodeficient rats. The results were compared with those of porcine periodontal ligament stem cells and porcine alveolar bone-marrow derived MSCs (66). Each cell pellet was transplanted into the bone defect, and CFU-F assays were used to quantify functional MSCs. All cell populations displayed colony formation and CFUF numbers were higher after culture in all cell populations. At 4 weeks, gross examination revealed that the defects in all groups were occupied by soft or hard tissue, and bone formation was confirmed by hematoxylin and eosin staining in all specimens (Fig. 6). Interestingly, there were no significant differences in new bone formation areas among the specimens. These results suggest that the potential for bone formation using DFSCs is similar to that obtained using periodontal ligament stem cells and bone marrowderived stem cells.

We next compared the potential of each identified human DFSC population (HDF1, 2, and 3) for bone formation using the same procedures (46), i.e., transplantation of a cell pellet into a surgically created full-thickness criticalsize partial defect in immunodeficient rats. In all groups, hematoxylin and eosin staining showed new bone formation and evidence of vascular invasion at 4 weeks posttransplantation (Fig. 7). The appearance of new bone formation was similar to that seen in intramembranous ossification, due to the absence of cartilage formation. The volume of new bone formation in animals transplanted with HDF1 or 2 cells was markedly greater than in those transplanted with HDF3 cells. Animals transplanted with control cells showed fibrous tissues and only very small amounts of bone at the defect site. These results suggest that although it is unclear whether transplanted cells directly differentiated into osteoblasts to create new bone, human DFSCs clearly support new bone formation.

Therapy using bone-tissue engineering requires the desired cells to be expanded in vitro until the number is sufficient for transplanting into the defect. Therefore, the next step in investigating DFSCs as a potential source is determining the optimal culture conditions for cell proliferation. The roles of various soluble factors in promoting osteogenic differentiation in bone marrowderived MSCs have been extensively studied $(67,68)$. However, little is known regarding how extracellular matrix promotes DFSC proliferation. We thus investigated culture systems in order to improve the DFSC yield via culturesurface modification (66). Four types of extracellular matrix (collagen type I, collagen type IV, laminin, fibronectin) were evaluated for their effects on cell growth and differentiation in DFSCs. We used single-cell cloning to harvest porcine DFSCs at the crown formation stage and confirmed osteogenic differentiation by analysis of alkaline 
phosphatase activity and gene expression. Collagen type I (Col-I) and fibronectin enhanced cell proliferation, but collagen type IV (Col-IV) inhibited cell growth. However, while both Col-I and Col-IV facilitated osteogenic differentiation, as shown by ALP activity, fibronectin did not. Interestingly, laminin inhibited both cell growth and osteogenic differentiation. It is interesting that human DFSCs also showed reduced cell adhesion on laminin, in addition to small cell size and actin stress fibers (Morsczeck, unpublished data). In an unpublished study, human DFSCs showed reduced potential for cell proliferation on laminin, as compared with cells on normal cell culture surfaces. Although a previous study of differentiated human DFSCs showed increased expression of laminin genes after osteogenic differentiation (56), DFSCs do not strongly interact with this extracellular matrix protein. These results suggest that Col-I is effective for both cell growth and differentiation of DFSCs into osteogenic lineage (66). If the number of undifferentiated DFSCs must be rapidly increased, fibronectin may be useful in promoting their growth. However, it is difficult to maintain MSCs in culture using serum, because serum contains growth factors that drive differentiation. We thus need to further explore optimal culture conditions for maintaining and expanding MSCs.

\section{Periodontal tissue engineering}

The periodontium is a topographically complex tissue consisting of soft and mineralized connective tissue and epithelium. We propose that there are four important factors in achieving successful periodontal regeneration. First, a functional epithelial seal must be present to prevent the migration of epithelial cells into periodontal defects. Second, new acellular cementum must be regenerated on the root surface. Third, alveolar bone height needs to be restored. Finally, new Sharpey fibers must be inserted into the newly formed root cementum. Recently, new techniques of cell transplantation have been developed to regenerate periodontium.

Periodontal ligament stem cells are a candidate cell source for periodontal regeneration. Human periodontal ligament stem cells (PDLCs) have previously been successfully isolated from extracted human teeth (10). Ex vivo-expanded PDLCs are capable of regenerating a typical cementum/periodontal ligament-like structure when transplanted into immunocompromised mice using hydroxyapatite/tricalcium phosphate (HA/TCP) as a carrier (10). Because of their periodontal ligament derivation and their capacity to differentiate into osteoblasts, cementoblasts, and fibroblasts, PDLCs were the first candidate stem cells for periodontal tissue engineering (69). More importantly, these cells have the potential to form collagen fibers and generate cementum/PDL-like structures in vivo and, thus, serve as reliable sources for periodontal tissue reconstruction (69). Nondental stem cells such as bone marrow mesenchymal stem cells (70), adipose-derived stem cells (71), embryonic stem cells (72), and induced pluripotent stem cells (iPS) (73) have also been investigated for periodontal regeneration. These cells all have the potential for differentiating into osteoblasts, cementoblasts, and fibroblasts, and to form cementum/PDL-like structures under appropriate conditions. Cultured periosteum is another possible cell source for periodontal regeneration. Mizuno et al. (73) grafted autologous cultured cell membrane derived from periosteum into a surgically created class III furcation defect in dogs. The formation of cementum, periodontal ligament-like tissues, and alveolar bone was evident 3 months after the grafting procedure. Another research group reported a treatment using periosteum-derived cells in human periodontal disease. Yamamiya et al. (3) showed that cultured periosteum combined with platelet-rich plasma and hydroxyapatite resulted in clinical improvements in human infrabony defects (3).

At present, bone marrow-derived stromal cells and periodontal ligament stem cells are used as the cell source for periodontal regeneration. As mentioned above, because periodontium originates from the DF, DFSCs could become an alternative cell source for periodontal regeneration therapy. We believe that further investigation of this potential is warranted.

Initially, we sought to generate whole tooth using the classical tissue engineering techniques developed by the Forsyth Group (74). However, we experienced difficulties in developing a method to generate a whole tooth using postnatal dental stem cells $(7,75-79)$. As an alternative to whole tooth replacement, we envisage partial replacement of the tooth by engineering the tooth root using DFSCs. This represents a root-shaped dentin mass associated with the periodontium, including cementum, PDL, and alveolar bone. Previously, we developed a method to generate dentin mass using the recombination technique. Enamel organ epithelium and dental pulp were isolated from the third molar of six-month-old pigs, and individual aggregated cell populations were recombined and transplanted into the omentum of immunodeficient rats. Enamel and dentin mass were observed, but the periodontium was not (unpublished data). As mentioned above, we developed this technique to expand DFSCs with the potential of cementum formation. To verify the feasibility of tooth root engineering, another experiment was designed to test whether cementum and PDL formation can be induced in the space between 
dentin and bone (80). Firstly, enamel organ epithelium, dental pulp, and dental follicle were harvested from the third molars of six-month-old pigs. DFSCs were then expanded in vitro. In an Eppendorf tube, subcultured DFSCs were seeded in the bottom of the tube, after which primary dental pulp cells, primary enamel organ epithelial cells, and subcultured DFSCs were successively added (Fig. 8). This recombination, which mimics the tooth primordia, was then inserted into a cavity inside the shaft of the bone and later transplanted into the omentum of 6-week-old immunocompromised rats.

After 24 weeks, a large amount of dentin mass was observed (Fig. 9A). In addition, odontoblasts were present along the formed dentin, a thick layer of cementum-like tissue was covered on the formed dentin (Fig. 9B), and spaces between the regenerated dentin and bone were filled with connective tissues (Fig. 9C). Collagen fiber-like

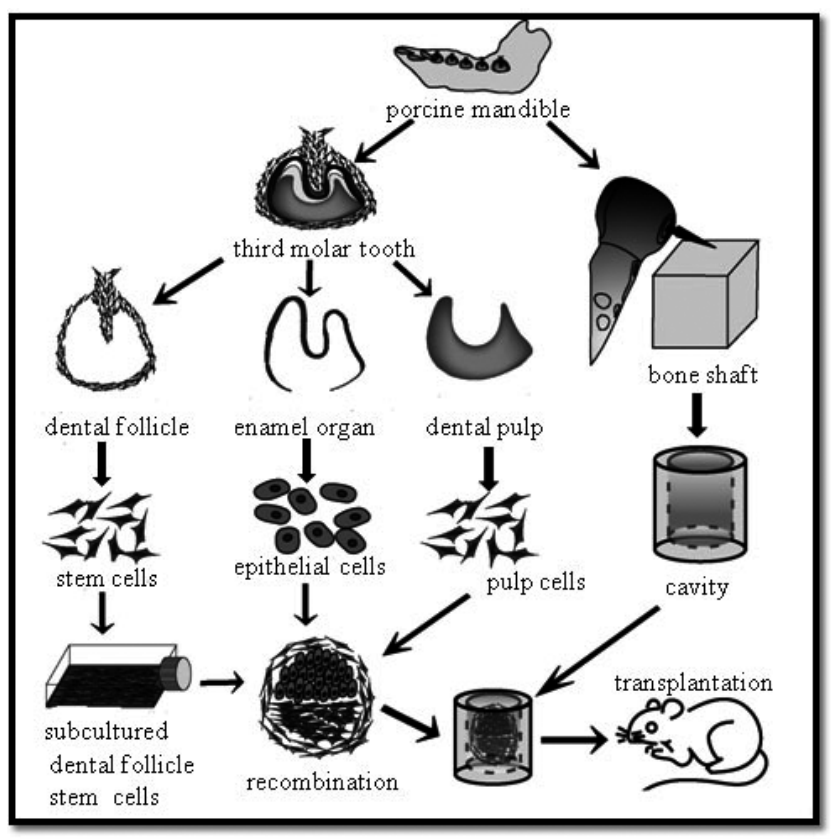

Fig. 8 Schematic diagram of procedure used to generate engineered dental root analogue. The third molar tooth is harvested from the mandible of a 6-month-old pig to obtain dental follicle, dental pulp, and enamel organ, and each cell is independently isolated. DFSCs are subcultured only until sufficient cell numbers for periodontal tissue regeneration are obtained. The cylindrical bone cavity is made from pig mandibular bone shaft. Firstly, subcultured DFSCs are seeded at the bottom of the bone cavity. Then, dental pulp cells, enamel organ epithelial cells, and subcultured DFSCs are successively placed over the preceding layer. A mimic of the tooth germ is thus created with dental cell populations. tissues resembling the PDL were perpendicularly attached to the cementum-like layer (Fig.9C). However, collagen fiber-like tissues were not observed on the surface of cementum without bone anchorage (Fig. 9B). Histological analyses confirmed the possibility of producing periodontium from subcultured DFSCs (80). In addition, this recombination technique for regenerating tooth root could be used for transplantation into alveolar bone to restore tooth loss, while the crown is restored with traditional prosthodontic treatment. This is our new approach to regenerating tooth using postnatal dental stem cells.

\section{Conclusion}

We described DFSCs and their potential application in dental tissue engineering. DF is easily obtained from clinically discarded third molar extractions, and can be stored frozen for many years. As a potential cell source, dental stem cell banking may be a necessary step, and further progress on establishing individualized induced pluripotent stem cells for dental tissue regeneration is imminent. Therefore, DFSCs could be a useful cell source

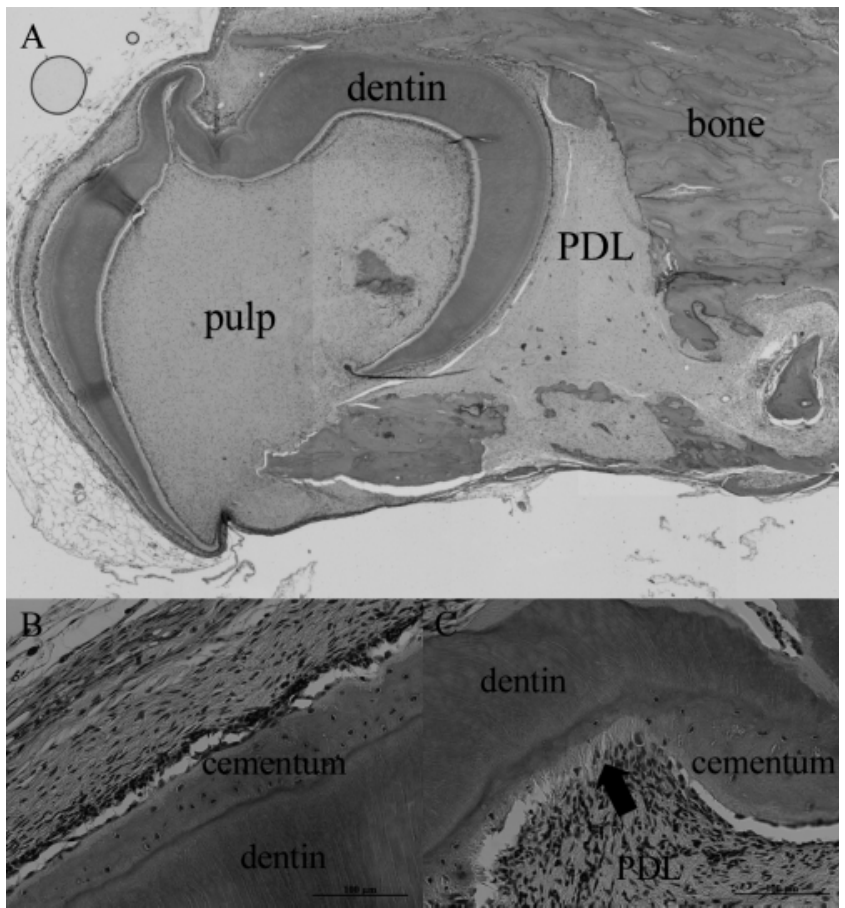

Fig. 9 (A) At 24 weeks after transplantation, a dental root structure consisting of dentin-pulp complex and cementum was observed. (B) At high magnification, cementum formation, but not periodontal ligament fibers, can be clearly identified on the dentin surface. (C) Periodontal ligament-like fibers were occasionally seen in the regenerated periodontium between cementum and bone. 
for tissue engineering therapy. Interestingly, DFSCs also have the potential to differentiate into neural cells, and future studies will undoubtedly investigate the potential of DFSCs as a cell source for treating diseases in other germ layers.

\section{References}

1. Langer R, Vacanti JP (1993) Tissue engineering. Science 260, 920-926.

2. Shayesteh YS, Khojasteh A, Soleimani M, Alikhasi M, Khoshzaban A, Ahmadbeigi N (2008) Sinus augmentation using human mesenchymal stem cells loaded into a beta-tricalcium phosphate/hydroxyapatite scaffold. Oral Surg Oral Med Oral Pathol Oral Radiol Endod 106, 203-209.

3. Yamamiya K, Okuda K, Kawase T, Hata K, Wolff LF, Yoshie H (2008) Tissue-engineered cultured periosteum used with platelet-rich plasma and hydroxyapatite in treating human osseous defects. J Periodontol 79, 811-818.

4. Honda MJ, Sumita Y, Kagami H, Ueda M (2005) Histological and immunohistochemical studies of tissue engineered odontogenesis. Arch Histol Cytol 68, 89-101.

5. Honda MJ, Tsuchiya S, Sumita Y, Sagara H, Ueda M (2007) The sequential seeding of epithelial and mesenchymal cells for tissue-engineered tooth regeneration. Biomaterials 28, 680-689.

6. Honda MJ, Fong H, Iwatsuki S, Sumita Y, Sarikaya M (2008) Tooth-forming potential in embryonic and postnatal tooth bud cells. Med Mol Morphol 41, 183-192.

7. Honda MJ, Ohara T, Sumita Y, Ogaeri T, Kagami H, Ueda M (2006) Preliminary study of tissueengineered odontogenesis in the canine jaw. J Oral Maxillofac Surg 64, 283-289.

8. Gronthos S, Mankani M, Brahim J, Robey PG, Shi S (2000) Postnatal human dental pulp stem cells (DPSCs) in vitro and in vivo. Proc Natl Acad Sci U S A 97, 13625-13630.

9. Honda MJ, Nakashima F, Satomura K, Shinohara Y, Tsuchiya S, Watanabe N, Ueda M (2007) Side population cells expressing ABCG2 in human adult dental pulp tissue. Int Endod J 40, 949-958.

10. Seo BM, Miura M, Gronthos S, Bartold PM, Batouli S, Brahim J, Young M, Robey PG, Wang CY, Shi $S$ (2004) Investigation of multipotent postnatal stem cells from human periodontal ligament. Lancet 364, 149-155.

11. Miura M, Gronthos S, Zhao M, Lu B, Fisher LW, Robey PG, Shi S (2003) SHED: stem cells from human exfoliated deciduous teeth. Proc Natl Acad
Sci U S A 100, 5807-5812.

12. Yao S, Pan F, Prpic V, Wise GE (2008) Differentiation of stem cells in the dental follicle. J Dent Res 87, 767-771.

13. Sonoyama W, Liu Y, Yamaza T, Tuan RS, Wang S, Shi S, Huang GT (2008) Characterization of the apical papilla and its residing stem cells from human immature permanent teeth: a pilot study. J Endod 34, 166-171.

14. Shinmura Y, Tsuchiya S, Hata K, Honda MJ (2008) Quiescent epithelial cell rests of Malassez can differentiate into ameloblast-like cells. J Cell Physiol 217, 728-738.

15. Thesleff I, Nieminen P (1996) Tooth morphogenesis and cell differentiation. Curr Opin Cell Biol 8, 844850.

16. Saygin NE, Giannobile WV, Somerman MJ (2000) Molecular and cell biology of cementum. Periodontol 2000 24, 73-98.

17. Diekwisch TG (2001) The developmental biology of cementum. Int J Dev Biol 45, 695-706.

18. Zeichner-David M, Oishi K, Su Z, Zakartchenko V, Chen LS, Arzate H, Bringas P Jr (2003) Role of Hertwig's epithelial root sheath cells in tooth root development. Dev Dyn 228, 651-663.

19. Bosshardt DD, Schroeder HE (1996) Cementogenesis reviewed: a comparison between human premolars and rodent molars. Anat Rec 245, 267-292.

20. Chai Y, Jiang X, Ito Y, Bringas P Jr, Han J, Rowitch DH, Soriano P, McMahon AP, Sucov HM (2000) Fate of the mammalian cranial neural crest during tooth and mandibular morphogenesis. Development 127, 1671-1679.

21. Cho MI, Garant PR (1988) Ultrastructural evidence of directed cell migration during initial cementoblast differentiation in root formation. J Periodontal Res 23, 268-276.

22. Cho MI, Garant PR (2000) Development and general structure of the periodontium. Periodontol 2000 24, 9-27.

23. Cahill DR, Marks SC Jr (1980) Tooth eruption: evidence for the central role of the dental follicle. J Oral Pathol 9, 189-200.

24. Marks SC Jr, Cahill DR (1984) Experimental study in the dog of the non-active role of the tooth in the eruptive process. Arch Oral Biol 29, 311-322.

25. Ten Cate AR (1997) The development of the periodontium - a largely ectomesenchymally derived unit. Periodontol 2000 13, 9-19.

26. Wise GE (2009) Cellular and molecular basis of tooth 
eruption. Orthod Craniofac Res 12, 67-73.

27. Wise GE, Frazier-Bowers S, D'Souza RN (2002) Cellular, molecular, and genetic determinants of tooth eruption. Crit Rev Oral Biol Med 13, 323-334.

28. Baykul T, Saglam AA, Aydin U, Başak K (2005) Incidence of cystic changes in radiographically normal impacted lower third molar follicles. Oral Surg Oral Med Oral Pathol Oral Radiol Endod 99, 542-545.

29. Slater LJ (2000) Dentigerous cyst versus dental follicle. Br J Oral Maxillofac Surg 38, 402.

30. Pittenger MF, Mackay AM, Beck SC, Jaiswal RK, Douglas R, Mosca JD, Moorman MA, Simonetti DW, Craig S, Marshak DR (1999) Multilineage potential of adult human mesenchymal stem cells. Science 284, 143-147.

31. Gang EJ, Jeong JA, Hong SH, Hwang SH, Kim SW, Yang IH, Ahn C, Han H, Kim H (2004) Skeletal myogenic differentiation of mesenchymal stem cells isolated from human umbilical cord blood. Stem Cells 22, 617-624.

32. Sanchez-Ramos J, Song S, Cardozo-Pelaez F, Hazzi C, Stedeford T, Willing A, Freeman TB, Saporta S, Janssen W, Patel N, Cooper DR, Sanberg PR (2000) Adult bone marrow stromal cells differentiate into neural cells in vitro. Exp Neurol 164, 247-256.

33. Le Blanc K, Rasmusson I, Sundberg B, Götherström C, Hassan M, Uzunel M, Ringdén O (2004) Treatment of severe acute graft-versus-host disease with third party haploidentical mesenchymal stem cells. Lancet 363, 1439-1441.

34. Frank MH, Sayegh MH (2004) Immunomodulatory functions of mesenchymal stem cells. Lancet 363, 1411-1412.

35. Small SA (2001) Age-related memory decline: current concepts and future directions. Arch Neurol 58, 360-364.

36. Secco M, Zucconi E, Vieira NM, Fogaça LL, Cerqueira A, Carvalho MD, Jazedje T, Okamoto OK, Muotri AR, Zatz M (2008) Multipotent stem cells from umbilical cord: cord is richer than blood! Stem Cells 26, 146-150.

37. Ishige I, Nagamura-Inoue T, Honda MJ, Harnprasopwat R, Kido M, Sugimoto M, Nakauchi H, Tojo A (2009) Comparison of mesenchymal stem cells derived from arterial, venous, and Wharton's jelly explants of human umbilical cord. Int J Hematol 90, 261-269.

38. Yokoi T, Saito M, Kiyono T, Iseki S, Kosaka K, Nishida E, Tsubakimoto T, Harada H, Eto K, Noguchi T, Teranaka T (2007) Establishment of immortalized dental follicle cells for generating periodontal ligament in vivo. Cell Tissue Res 327, 301-311.

39. Handa K, Saito M, Tsunoda A, Yamauchi M, Hattori S, Sato S, Toyoda M, Teranaka T, Narayanan AS (2002) Progenitor cells from dental follicle are able to form cementum matrix in vivo. Connect Tissue Res 43, 406-408.

40. Handa K, Saito M, Yamauchi M, Kiyono T, Sato S, Teranaka T, Sampath Narayanan A (2002) Cementum matrix formation in vivo by cultured dental follicle cells. Bone 31, 606-611.

41. Jo YY, Lee HJ, Kook SY, Choung HW, Park JY, Chung JH, Choung YH, Kim ES, Yang HC, Choung PH (2007) Isolation and characterization of postnatal stem cells from human dental tissues. Tissue Eng 13, 767-773.

42. Morsczeck C, Götz W, Schierholz J, Zeilhofer F, Kühn U, Möhl C, Sippel C, Hoffmann KH (2005) Isolation of precursor cells (PCs) from human dental follicle of wisdom teeth. Matrix Biol 24, 155-165.

43. Luan X, Ito Y, Dangaria S, Diekwisch TG (2006) Dental follicle progenitor cell heterogeneity in the developing mouse periodontium. Stem Cells Dev 15, 595-608.

44. Kémoun P, Laurencin-Dalicieux S, Rue J, Farges JC, Gennero I, Conte-Auriol F, Briand-Mesange F, Gadelorge M, Arzate H, Narayanan AS, Brunel G, Salles JP (2007) Human dental follicle cells acquire cementoblast features under stimulation by BMP2/-7 and enamel matrix derivatives (EMD) in vitro. Cell Tissue Res 329, 283-294.

45. Lindroos B, Mäenpää K, Ylikomi T, Oja H, Suuronen R, Miettinen S (2008) Characterisation of human dental stem cells and buccal mucosa fibroblasts. Biochem Biophys Res Commun 368, 329-335.

46. Honda MJ, Imaizumi M, Suzuki H, Ohshima S, Tsuchiya S, Satomura K (2010) Stem cells isoalted human dental follicle have osteogenic potential. Oral Surg Oral Med Oral Pathol Oral Radiol Endod. (in press)

47. Gao FB, Raff M (1997) Cell size control and a cellintrinsic maturation program in proliferating oligodendrocyte precursor cells. J Cell Biol 138, 1367-1377.

48. Barrandon Y, Green H (1985) Cell size as a determinant of the clone-forming ability of human keratinocytes. Proc Natl Acad Sci U S A 82, 53905394.

49. Angello JC, Pendergrass WR, Norwood TH, 
Prothero J (1987) Proliferative potential of human fibroblasts: an inverse dependence on cell size. J Cell Physiol 132, 125-130.

50. Watt FM, Green H (1981) Involucrin synthesis is correlated with cell size in human epidermal cultures. J Cell Biol 90, 738-742.

51. Dazard JE, Piette J, Basset-Seguin N, Blanchard JM, Gandarillas A (2000) Switch from p53 to MDM2 as differentiating human keratinocytes lose their proliferative potential and increase in cellular size. Oncogene 19, 3693-3705.

52. Kim HS, Jun Song X, de Paiva CS, Chen Z, Pflugfelder SC, Li DQ (2004) Phenotypic characterization of human corneal epithelial cells expanded ex vivo from limbal explant and single cell cultures. Exp Eye Res 79, 41-49.

53. Lin NH, Menicanin D, Mrozik K, Gronthos S, Bartold PM (2008) Putative stem cells in regenerating human periodontium. J Periodontal Res 43, 514-523.

54. Farkas LM, Huttner WB (2008) The cell biology of neural stem and progenitor cells and its significance for their proliferation versus differentiation during mammalian brain development. Curr Opin Cell Biol 20, 707-715.

55. Tsuchiya S, Honda MJ, Shinohara Y, Saito M, Ueda M (2008) Collagen type I matrix affects molecular and cellular behavior of purified porcine dental follicle cells. Cell Tissue Res 331, 447-459.

56. Morsczeck C, Moehl C, Götz W, Heredia A, Schäffer TE, Eckstein N, Sippel C, Hoffmann KH (2005) In vitro differentiation of human dental follicle cells with dexamethasone and insulin. Cell Biol Int 29, 567-575.

57. Morsczeck C, Schmalz G, Reichert TE, Völlner F, Saugspier M, Viale-Bouroncle S, Driemel O (2009) Gene expression profiles of dental follicle cells before and after osteogenic differentiation in vitro. Clin Oral Investig 13, 383-391.

58. Sessarego N, Parodi A, Podestà M, Benvenuto F, Mogni M, Raviolo V, Lituania M, Kunkl A, Ferlazzo G, Bricarelli FD, Uccelli A, Frassoni F (2008) Multipotent mesenchymal stromal cells from amniotic fluid: solid perspectives for clinical application. Haematologica 93, 339-346.

59. Tomar GB, Srivastava RK, Gupta N, Barhanpurkar AP, Pote ST, Jhaveri HM, Mishra GC, Wani MR (2010) Human gingiva-derived mesenchymal stem cells are superior to bone marrow-derived mesenchymal stem cells for cell therapy in regenerative medicine. Biochem Biophys Res
Commun 393, 377-383.

60. Crisan M, Yap S, Casteilla L, Chen CW, Corselli M, Park TS, Andriolo G, Sun B, Zheng B, Zhang L, Norotte C, Teng PN, Traas J, Schugar R, Deasy BM, Badylak S, Buhring HJ, Giacobino JP, Lazzari L, Huard J, Péault B (2008) A perivascular origin for mesenchymal stem cells in multiple human organs. Cell Stem Cell 3, 301-313.

61. Lin YF, Jing W, Wu L, Li XY, Wu Y, Liu L, Tang W, Long J, Tian WD, Mo XM (2008) Identification of osteo-adipo progenitor cells in fat tissue. Cell Prolif 41, 803-812.

62. Tang W, Zeve D, Suh JM, Bosnakovski D, Kyba M, Hammer RE, Tallquist MD, Graff JM (2008) White fat progenitor cells reside in the adipose vasculature. Science 322, 583-586.

63. Rodeheffer MS, Birsoy K, Friedman JM (2008) Identification of white adipocyte progenitor cells in vivo. Cell 135, 240-249.

64. Young HE, Black AC Jr (2004) Adult stem cells. Anat Rec A Discov Mol Cell Evol Biol 276, 75-102.

65. Mao JJ, Giannobile WV, Helms JA, Hollister SJ, Krebsbach PH, Longaker MT, Shi S (2006) Craniofacial tissue engineering by stem cells. J Dent Res 85, 966-979.

66. Tsuchiya S, Ohshima S, Yamakoshi Y, Simmer JP, Honda MJ (2010) Osteogenic differentiation capacity of porcine dental follicle progenitor cells. Connect Tissue Res 51, 197-207.

67. Klees RF, Salasznyk RM, Vandenberg S, Bennett K, Plopper GE (2007) Laminin-5 activates extracellular matrix production and osteogenic gene focusing in human mesenchymal stem cells. Matrix Biol 26, 106-114.

68. Salasznyk RM, Williams WA, Boskey A, Batorsky A, Plopper GE (2004) Adhesion to vitronectin and collagen I promotes osteogenic differentiation of human mesenchymal stem cells. J Biomed Biotechnol 2004, 24-34.

69. Liu Y, Zheng Y, Ding G, Fang D, Zhang C, Bartold PM, Gronthos S, Shi S, Wang S (2008) Periodontal ligament stem cell-mediated treatment for periodontitis in miniature swine. Stem Cells 26, 1065-1073.

70. Kawaguchi H, Hirachi A, Hasegawa N, Iwata T, Hamaguchi H, Shiba H, Takata T, Kato Y, Kurihara H (2004) Enhancement of periodontal tissue regeneration by transplantation of bone marrow mesenchymal stem cells. J Periodontol 75, 12811287.

71. Tobita M, Uysal AC, Ogawa R, Hyakusoku H, 
Mizuno H (2008) Periodontal tissue regeneration with adipose-derived stem cells. Tissue Eng Part A 14, 945-953.

72. Inanç B, Elçin AE, Unsal E, Balos K, Parlar A, Elçin YM (2008) Differentiation of human embryonic stem cells on periodontal ligament fibroblasts in vitro. Artif Organs 32, 100-109.

73. Duan X, Tu Q, Zhang J, Ye J, Sommer C, Mostoslavsky G, Kaplan D, Yang P, Chen J (2011) Application of induced pluripotent stem (iPS) cells in periodontal tissue regeneration. J Cell Physiol 226, 150-157.

74. Young CS, Terada S, Vacanti JP, Honda M, Bartlett JD, Yelick PC (2002) Tissue engineering of complex tooth structures on biodegradable polymer scaffolds. J Dent Res 81, 695-700.

75. Honda MJ, Shinohara Y, Hata KI, Ueda M (2007) Subcultured odontogenic epithelial cells in combination with dental mesenchymal cells produce enamel-dentin-like complex structures. Cell Transplant 16, 833-847.
76. Honda MJ, Shinohara Y, Sumita Y, Tonomura A, Kagami H, Ueda M (2006) Shear stress facilitates tissue-engineered odontogenesis. Bone 39, 125133.

77. Honda MJ, Shinmura Y, Shinohara Y (2009) Enamel tissue engineering using subcultured enamel organ epithelial cells in combination with dental pulp cells. Cells Tissues Organs 189, 261-267.

78. Sumita Y, Honda MJ, Ohara T, Tsuchiya S, Sagara H, Kagami H, Ueda M (2006) Performance of collagen sponge as a 3-D scaffold for tooth-tissue engineering. Biomaterials 27, 3238-3248.

79. Sumita Y, Tsuchiya S, Asahina I, Kagami H, Honda MJ (2009) The location and characteristics of two populations of dental pulp cells affect tooth development. Eur J Oral Sci 117, 113-121.

80. Honda MJ, Tsuchiya S, Shinohara Y, Shinmura Y, Sumita Y (2010) Recent advance in engineering of tooth and tooth structures using postnatal dental cells. Jpn Dent Sci Rev 46, 54-66. 